\title{
Self-reinforcing Mechanisms in a Multi- technology Industry: Understanding Sustained Technological Variety in a Context of Path Dependency
}

Ksenia Onufrey and Anna Bergek

\section{Linköping University Post Print}

\section{Tweet}

N.B.: When citing this work, cite the original article.

This is an electronic version of an article published in:

Ksenia Onufrey and Anna Bergek, Self-reinforcing Mechanisms in a Multi-technology Industry: Understanding Sustained Technological Variety in a Context of Path Dependency, 2015, Industry and Innovation, (22), 6, 523-551.

Industry and Innovation is available online at informaworld ${ }^{\mathrm{TM}}$ :

http://dx.doi.org/10.1080/13662716.2015.1100532

Copyright: Taylor \& Francis (Routledge): SSH Titles

http://www.routledge.com/

Postprint available at: Linköping University Electronic Press

http://urn.kb.se/resolve?urn=urn:nbn:se:liu:diva-123163 


\title{
Self-reinforcing mechanisms in a multi-technology industry: understanding sustained technological variety in a context of path dependency
}

Ksenia Onufrey ${ }^{\mathrm{a}, *}$ and Anna Bergek ${ }^{\mathrm{b}}$

${ }^{a}$ Department of Management and Engineering, Linköping University, SE-581 83 Linköping, Sweden.Email: ksenia.onufrey@liu.se,

${ }^{\mathrm{b}}$ Department of Management and Engineering and the KITE Research Program, Linköping University,SE-58183 Linköping, Sweden.Email: anna.bergek@liu.se

*Corresponding author

\begin{abstract}
This paper studies self-reinforcing mechanisms in multi-technology industries, i.e. industries in which technological lock-in does not occur and several technologies continue to co-exist. The purpose of this paper is to investigate what kind of self-reinforcing mechanisms can be present in such industries and explain how multiple paths can co-exist and interact in a context of self-reinforcement and, ultimately, path dependency. Building on the empirical example of the lighting industry, the paper shows that all previously recognized types of selfreinforcing mechanisms can be present in a multi-technology industry. However, in addition to the path-internal positive feedbacks and cross-path negative externalities identified in single-path settings, multi-technology industries also experience positive cross-path externalities that create a symbiotic relationship between alternatives and allow for the reproduction of the same development pattern across technologies. Due to the existence of such non-negative technology interactions, multi-technology industries can be path dependent while still retaining technological variety.
\end{abstract}

Keywords: self-reinforcing mechanisms, path dependency, multi-technology industries, lighting industry 


\section{Introduction}

The evolution of technologies and industries often shows signs of self-sustained development patterns, where some choices or events are reproduced over time (Arthur 1994, Dobusch and Schüßler 2012). In technology development studies, the driving forces behind this kind of processes are referred to as self-reinforcing mechanisms (Araujo and Harrison 2002).

Together with persistence, such self-reinforcing mechanisms are the key components of path dependency (Sydow, Schreyögg, and Koch 2009), a concept that over the past thirty years has been developed to explain historically bounded development processes (Arthur 1994, David 1985)

Most researchers agree that the main self-reinforcing mechanisms are coordination effects, complementarity effects, expectation effects and investment and learning effects (Dobusch and Schüßler 2012). These mechanisms have been described both at the micro-level of organizations (Sydow, Schreyögg, and Koch 2009) and at the meso-level of technological fields and industries (Arthur 1989, Dobusch and Schüßler 2012). This paper is focused on technological path dependency at the industry-level, where self-reinforcing mechanisms can be addressed by recognizing development patterns that are common to most, if not all, industry actors (e.g. Mazzoleni 1997).

In the existing literature, path dependency and self-reinforcing mechanisms are typically addressed in a context where competition is the only possible relation between different paths (cf. David 1985, Cecere 2009, Cowan and Gunby 1996) and where the main possible outcome is lock-in, i.e. where only one, potentially inferior, winning path remains in the end (Vergne and Durand 2010). Self-reinforcing mechanisms play a crucial role here, by strengthening the winner-to-be while weakening all other alternatives. 
In contrast, the possibility that lock-in can be avoided, i.e. that several paths can co-exist over sustained periods of time and experience non-competitive interaction even in a context of path dependency, has not been considered. Yet, empirical evidence suggests that technological variety can continue to exist for long time periods even in companies and industries that otherwise show strong signs of path dependency in the form of persistence and overall stability (Bergek and Onufrey 2014). This raises a number of questions with regard to selfreinforcing mechanisms as one of the key aspects of path dependency. Do such mechanisms exist also in multi-technology industries and, in that case, what do they look like and what makes it possible for such industries to sustain technological diversity and avoid technological lock-in?

Based on the empirical evidence from the lighting industry, the purpose of this paper is to investigate what kind of self-reinforcing mechanisms can be present in multi-technology industries and explain how multiple paths can co-exist and interact in a context of selfreinforcement and, ultimately, path dependency.

\section{Theoretical framework}

\subsection{Weak and strong notions of path dependency}

In previous literature, the concept of path dependency has developed from a 'weak' notion that "history matters” to a much more complex, 'strong' notion, which includes two main components: persistence and self-reinforcing mechanisms (Bergek and Onufrey 2014, cf. also Sydow, Schreyögg, and Koch 2009). In the context of technological path dependency, persistence refers to "the existence and maintenance of a specific pattern of technological specialization” within companies or industries or, more specifically, to a stable pattern of repeated decisions and choices related to technology development or adoption (Bergek and Onufrey 2014, p. 1266, cf. also Fai 2003) and is, thus, closely associated with the notion of 
‘path’ as such (Bergek and Onufrey 2014). However, persistence (or, in other words, the existence of a technology path) is only a sign of past dependency (Antonelli 2009). To speak of path dependency, there also has to be a causal connection between earlier and later events. This is what is normally referred to as self-reinforcing mechanisms (cf., e.g., Dobusch and Schüßler 2012, Vergne and Durand 2010, Sydow, Schreyögg, and Koch 2009, Koch, Eisend, and Petermann 2009) and what is in focus in this paper.

In some recent path dependency literature, it has been argued that lock-in is also a necessary feature of path dependent processes (Vergne and Durand 2010). The argument is that selfreinforcing mechanisms are associated with a gradual decrease in available options until only one (often inferior) technology remains (David 1985, Arthur 1989, Cowan and Gunby 1996). ${ }^{1}$ Indeed, in this literature a path is normally seen as the result of an irreversible selection of an individual, “winning” technology at the level of a technology field or industry (Bergek and Onufrey 2014). However, the main argument of this paper is that persistence in combination with self-reinforcing mechanisms can exist also in multi-technology industries, i.e. industries where several technologies co-exist over sustained periods of time. This implies that we challenge the notion that lock-in is the only possible outcome of path dependent processes and instead focus on understanding how several paths can survive in parallel at the industry level and, more specifically, the role of self-reinforcing mechanisms in this.

\subsection{Self-reinforcing mechanisms: technology adoption vs. technology development}

As indicated above, self-reinforcing mechanisms can be defined as a set of forces or processes that reproduce a particular pattern of events, choices or activities over time (Araujo and Harrison 2002, Page 2006, Mahoney 2000) and explain the development from a set of initial

\footnotetext{
${ }^{1}$ Lock-in can, in turn, be categorized as $2^{\text {nd }}$ degree path dependency (lock-in to regrettable, but not inefficient, options) or $3^{\text {rd }}$ degree path dependency (lock-in to inefficient options, which could have been avoided) (Liebowitz and Margolis 1995).
} 
conditions to a specific outcome (Dobusch and Kapeller 2013), for example increasing stability and lock-in (Dobusch and Schüßler 2012). When self-reinforcing mechanisms are in place, each step taken in a certain direction makes it more probable that further steps will be taken in the same direction (Pierson 2000), i.e. once an initial choice is made, self-reinforcing mechanisms lead to repetition of that choice and eventually make it self-sustained (Arthur 1994, Araujo and Harrison 2002). They are, therefore, often described as feedback loops (Arthur 1994, Koch, Eisend, and Petermann 2009) or virtuous/vicious circles (Pierson 2000). The earliest studies of path dependency focused on "increasing returns to adoption" of technologies. Both Arthur (1989) and David (1985) studied cases of technology competition in which historical contingencies in combination with increasing returns to adoption led to market dominance of potentially inferior technologies (QWERTY in the example of David and VCR cassette recorders in the case of Arthur). These early examples of technology adoption are still widely cited (e.g. Page 2006, Pierson 2000, Vergne and Durand 2010, Garud, Kumaraswamy, and Karnøe 2010, Kay 2013, Liebowitz and Margolis 1995) and have become something of a hallmark of path dependency research. This implies that selfreinforcing mechanisms are primarily associated with technology adoption, i.e. the pattern that they reproduce is the adoption of one specific technology or product before other alternatives.

In later writings the adoption focus has become less pronounced. Most noticeably, the concept of increasing returns to adoption has been gradually replaced with more general terms, such as self-reinforcing mechanisms, which are not only related to technology adoption and distribution, but can include technology development in firms and industries as well. For example, in their recent conceptualization of path dependency Dobusch and Schüßler (2012) consider the organizational context, which includes (but is not limited to) technology development-related mechanisms. Furthermore, there are some empirical studies of path 
dependency in technology development, for example case studies of technology development in firms (e.g. Araujo and Harrison 2002) and industry consortia (e.g. Sydow et al. 2012) as well as studies of organizational path dependency (Sydow, Schreyögg, and Koch 2009, Schreyögg, Sydow, and Holtmann 2011). Nevertheless, the idea of technology developmentrelated self-reinforcing mechanisms has been much less elaborated on and remains much less explicit in the path dependency literature than adoption-related mechanisms.

This is somewhat problematic when considering that the wider technology management literature indicates that some kind of self-reinforcing mechanisms are in place that may result in a repeated pattern of actions also with regard to technology development. In particular, it emphasizes the tendency of established companies to focus their development efforts on established product architectures (Henderson and Clark 1990) and performance trajectories (Tushman and Anderson 1986, Dosi 1982) or, more generally, to be characterized by a "local” search behavior (Rosenkopf and Almeida 2003, Stuart and Podolny 1996). Repeated choices are, thus, made in terms of allocation of resources to the exploitation of established technologies and performance attributes rather than the exploration of new technological paths (Rosenkopf and Nerkar 2001, Christensen and Bower 1996, March 1991).

In the following, we elaborate further on this idea by explicitly distinguishing self-reinforcing mechanisms that are manifested in technology adoption from those manifested in technology development.

\subsection{Four types of self-reinforcing mechanisms}

In previous literature, four main types of self-reinforcing mechanisms are generally discussed (although sometimes under slightly different labels): coordination effects, complementarity effects, expectation effects and investment and learning effects. In line with the discussion in 
the previous section, we here argue that each of these mechanisms can manifest itself both as repeated technology adoption patterns and as repeated technology development patterns (see Table 1).

\subsubsection{Coordination effects}

Coordination effects refer to the utility of following the same course of actions as others (Arthur 1994, Dobusch and Schüßler 2012). The more actors make a similar choice or follow the same rule, the more efficient interaction between them can be (Sydow, Schreyögg, and Koch 2009). A well-known example of coordination effects - the right-hand traffic rule (e.g. Arthur 1994) - illustrates that as long as everyone follows the same principle (drive on the right-hand side of the street), all the participants get the benefit of predictability and safety.

With regard to technology adoption, coordination effects take the form of direct network effects, i.e. the attractiveness and usefulness of a product increase with an increasing number of adopters (Dobusch and Schüßler 2012). Here, the size of the user network defines the utility of the product (Katz and Shapiro 1985). With regard to technology development, coordination effects can be seen in, e.g., the advantages of following the same industry norms and standards and the coordination costs associated with switching to a new standard (Farrell and Saloner 1985).

\subsubsection{Complementarity effects}

Complementarity effects imply that the success of a technology depends on the development of complementary products, services or processes (Sydow, Schreyögg, and Koch 2009, Dobusch and Schüßler 2012).

With regard to technology adoption, complementarity effects are in place when the existence of high-quality complementary products positively affects the market adoption of a 
technology (Dobusch and Schüßler 2012). For example, spare parts or software often become cheaper and more readily available as the market expands, which increases the technology's attractiveness to new buyers and users (Farrell and Saloner 1985, Katz and Shapiro 1985). With regard to technology development, companies may enjoy complementarity effects in the form of vertically related products (Dobusch and Schüßler 2012) or resource complementarities originating from, e.g., related knowledge, manufacturing facilities or distribution channels (Teece 1986). Such complementarities make it more attractive for suppliers to continue to exploit and profit from established technologies than to develop new ones.

\subsubsection{Expectation effects}

Expectation effects are based on people's inclination to change their expectations depending on the expectations of others, i.e. individual preferences are to some extent based on others' future choices (Sydow, Schreyögg, and Koch 2009, Dobusch and Schüßler 2012). This kind of "going along” with others (Arthur 1994) makes expectation effects similar to coordination effects discussed above. However, under expectation effects agents do not derive any real utility, but rather seek a "softer” type of advantage - being on the winning side or avoiding being an outsider (Sydow, Schreyögg, and Koch 2009).

With regard to technology adoption, such legitimacy-seeking behaviour is seen when people adopt a technology because of a need for social belonging (Sydow, Schreyögg, and Koch 2009) or in order to create a positive image of themselves among their peers (Bollinger and Gillingham 2012). With regard to technology development, expectation effects manifest themselves as, for example, institutional isomorphism (DiMaggio and Powell 1983) or the diffusion of best practices (Sydow, Schreyögg, and Koch 2009). 


\subsubsection{Investment and learning effects}

Investment and learning effects refer to the accumulation of resources and knowledge that are specific to a particular product or technology and cannot be easily transferred to or reused in alternatives (Dobusch and Schüßler 2012).

With regard to technology adoption, an initial choice of a specific technology makes a user less prone to buying an alternative. Especially when high tech products are concerned, users have to invest in training and competence-building when they adopt a new technology, and by repeating the same technology choice they can exploit these investments further (Arthur 1996). Users also learn over time how the technology works. They thereby get used to it and are likely to stay loyal when new versions are introduced (Dobusch and Schüßler 2012). Other well-known investment and learning effects are economies of scale and experience, i.e. increased diffusion stimulates learning-by-using and learning-by-doing, which result in cost decreases and product performance increases and, thus, in further incentives for customers to adopt the technology (Arthur 1994, Cowan and Gunby 1996).

With regard to technology development, the need for high initial investments (up-front costs or sunk costs) creates incentives to continue along the chosen path. Further, due to learningby-doing effects related to technology development, i.e. when companies learn as a "byproduct” of manufacturing (Arrow 1962), more new problems and bottlenecks are identified the more experience a company has of a technology. This sustains companies' interest in developing the same technology further and encourages local learning. In addition, companies develop skills and routines that are adapted to their current resources (Grant 1991). Refining previous successes by focusing learning efforts on existing technologies requires less effort than exploring new options (Sydow, Schreyögg, and Koch 2009), which is one reason why 
companies, as mentioned above, tend to engage in local search, i.e. to look for new opportunities close to their existing technology base (Foray 1997).

Table 1. Examples of manifestations of different types of self-reinforcing mechanisms in adoption and development respectively

\begin{tabular}{|c|c|c|}
\hline & Technology adoption & Technology development \\
\hline Coordination effects & Direct network effects & Standardization advantages \\
\hline \multirow[t]{2}{*}{ Complementarity effects } & \multirow[t]{2}{*}{ Product complementarities } & Vertical product interdependencies \\
\hline & & Resource complementarities \\
\hline Expectations effects & $\begin{array}{l}\text { Legitimation by “going along” with } \\
\text { others }\end{array}$ & $\begin{array}{l}\text { Institutional isomorphism and diffusion } \\
\text { of best practises }\end{array}$ \\
\hline \multirow[t]{4}{*}{ Investment and learning effects } & \multirow{2}{*}{$\begin{array}{l}\text { Economies of scale and experience } \\
\text { leading to better performance and lower } \\
\text { cost }\end{array}$} & Sunk costs \\
\hline & & $\begin{array}{l}\text { Learning by doing, identifying new } \\
\text { problems and bottlenecks }\end{array}$ \\
\hline & $\begin{array}{l}\text { Investments in training, competence- } \\
\text { building }\end{array}$ & Local search \\
\hline & Customer learning and loyalty & \\
\hline
\end{tabular}

\subsection{Positive feedbacks and negative externalities}

As the definition suggests, the forces of self-reinforcement make a certain alternative increasingly attractive (Vergne and Durand 2010). The term 'positive feedbacks', which is sometimes used almost synonymously to the term self-reinforcing mechanism (e.g. Pierson 2000, Dobusch and Schüßler 2012), reflects this logic well. Positive feedbacks can be seen as internal to a particular technology in the sense that it is the choice to continue to adopt or develop a technology that is reinforced.

However, each positive feedback also has a "mirror" effect on other technologies. In the literature, these mirror effects are usually termed "negative externalities” and are described as self-reinforcing mechanisms that decrease the relative attractiveness of competing alternatives once a positive feedback loop has been established for one of them (Vergne and Durand 2010). As Page (2006) showed using the QWERTY example, the same process that initiates a positive feedback if considered from the point of view of the "winner-to-be” creates a 
matching negative externality if considered from the point of view of other technologies. Negative externalities can therefore be seen as influences across paths.

\subsection{Exploring self-reinforcing mechanisms in a multi-path setting: research questions}

A common interpretation of positive feedbacks and negative externalities as mirror processes is that once one option experiences self-reinforcing mechanisms, all other alternatives will suffer and eventually exit the competition. This is in line with the single-path view put forward in most of the path dependency literature referred to above, which focuses on cases in which a single winning technology (or a more general pattern of activity) outcompetes all other alternatives and in which further developments proceed along a narrowing path, eventually resulting in a more or less irreversible lock-in situation (Bergek and Onufrey 2014). For example, the concept of increasing returns to adoption has primarily been used to explain the outcome of technological competition in terms of lock-in to (inferior) technologies that for some (often more or less random) reason got ahead and stayed ahead (cf. Arthur 1989, Cowan 1990). Once lock-in has occurred, actors are largely unable to deviate from the established path unless they are subjected to some kind of external shock (Vergne and Durand 2010, Garud, Kumaraswamy, and Karnøe 2010, Sydow, Schreyögg, and Koch 2009). Even if some of the literature acknowledges that new paths can be created (cf., e.g. Garud, Kumaraswamy, and Karnøe 2010), the co-existence of several technologies is generally considered to be a temporary phenomenon or an exceptional situation associated with inefficiency due to an inability to take a full advantage of economies of scale and network externalities (Foray 1997).

However, this view does not correspond well with an empirical reality where there are multitechnology companies (Granstrand and Sjölander 1990, Granstrand, Patel, and Pavitt 1997), widely defined sectors (Rao, Vemuri, and Galvin 2004) and industries (Onufrey 2014) in 
which several technological paths co-exist and are sustained over time. One example of the latter is the lighting industry, where a number of different lamp technologies have been developed and introduced since the 1870s and now co-exist in the major lighting companies as well as in the market place. In spite of its multi-technology character, this industry is characterized by substantial technological persistence as well as by an overall stability in terms of leading companies (Bergek and Onufrey 2014). It, thus, shows strong signs of path dependency, although it cannot be described as locked in to one technological path. To allow for that, self-reinforcing mechanisms - a central component of path dependency - need to be different in multi-technology industries as compared with industries characterized by lock-in to one single technological path. The difference can be either in the mechanisms associated with each path, or in the ways paths affect each other (i.e. cross-path externalities), or both.

Against this discussion, we will answer the following research questions in order to achieve the purpose of this paper:

(1) What kind of self-reinforcing mechanisms (with respect to different types and technology development vs adoption manifestations) can be present in a multitechnology industry, i.e. in cases where the outcome is not lock-in to one single technology?

(2) What is the role of self-reinforcing mechanisms in enabling the survival of several technological alternatives, i.e. in avoiding technological lock-in?

\section{Research design}

Path dependency is an increasingly popular concept among scholars which opens for a number of debates that concern not only theoretical boundaries and contents of the concept, but also appropriate methodological tools (Vergne and Durand 2010, Garud, Kumaraswamy, 
and Karnøe 2010). As Dobush and Kapeller (2013) have recently summarized, no established methodology can be considered as especially appropriate for studying path dependency in general or self-reinforcing mechanisms in particular. Instead, ”the identification and investigation of particular positive feedback effects and their impact on the overall development is [considered to be] an empirical task, one that allows for applying a broad repertoire of methods” (Dobusch and Kapeller 2013. p. 295). In this paper, we use the single retrospective case study methodology where we apply a theory-based conceptualization of self-reinforcing mechanisms to a multi-technology industry.

\subsection{Case selection}

Case selection was a result of theoretical sampling. The appropriate industry should satisfy two main requirements. First, it should be characterized by a presence of several co-existing technological paths. Second, the industry should be path dependent. However, in a strict sense an industry can be defined as path dependent only after self-reinforcing mechanisms have been identified (Sydow, Schreyögg, and Koch 2009), which is the task to be accomplished in this paper. Therefore, we decided to study an industry that at least had shown strong signs of path dependency in terms of, e.g., persistence and historically bounded development: the lighting industry (cf. Bergek and Onufrey 2014).

\subsection{Data collection}

Data was collected in several steps. First, technical reports, industry studies and annual reports of leading manufacturers were studied in order to create an overall picture of the industry. In addition, at an early stage of data gathering we conducted a number of interviews with representatives from industry actors. The interviews were used to confirm general patterns of industry development and to provide specific information with regard to some of 
the mechanisms. For example, interviews with producers (Osram and Philips) were focused on the commonalities and differences between different lighting technologies; wholesalers (IKEA and ICA) and a construction company (Lambertsson) were interviewed with regard to their view on customer preferences and supplier relations; and an interview with an industry association (Global Lighting Association) highlighted relevant technology development issues at the industry level. In all interviews, the influence of LED technology on the lighting industry was discussed.

Second, we proceeded with looking for repeated patterns and root-cause relationships based on which we could identify self-reinforcing mechanisms. During that step, the following data sources were studied:

1. The contents of the Lighting Research and Technology Journal for the period of 19692012 were analyzed, which included a review of all paper titles (over 1000 papers), screening of abstracts, and, in some cases, full texts of technology-related articles (around 200 articles), and a careful study of technology and industry overview papers (around 20 articles).

2. Paper titles in the Journal of Light and Visual Environment for the period of 19772012 were screened, and the most relevant technology-oriented papers (around 20 articles) were studied.

3. Industry reports, reports from the IEA and previous research on the development and diffusion of new lighting technologies, especially CFLs, were analyzed.

Finally, a focused search with respect to particular mechanisms used as examples in the paper (e.g., patent searches in order to illustrate reference patterns) was performed in order to ensure their reliability. 
Appendix 1 summarizes the data sources referred to in the article. For each source, it is clarified what kind of information was used as an input for analysis and how data was interpreted. As can be seen in the Appendix 1, most of the processes underlying the identified mechanisms are referred to across several different sources. This confirms that the mechanisms discussed in the paper are well established and generally recognized. ${ }^{2}$ With the exception of Menanteau and Lefebvre (2000), the sources did not operate with the notion of self-reinforcing mechanisms, but rather presented reasons for a continued dominance of incandescent lamps or barriers for other technologies. The sources also tended to focus on one technology, without much cross-technology comparison. It was, thus, an analytical task (performed for the purpose of this paper) to apply the path dependency theoretical framework to the data in order to identify and characterize self-reinforcing mechanisms and make crosstechnology connections (e.g. to discover mechanisms that first affected CFL and were later reproduced with LED).

\subsection{Data analysis}

The analysis of the data was performed by matching identified patterns with different types of self-reinforcing mechanisms, as they were described in previous research. Co-authors, independently of each other, tagged identified mechanisms along the characteristics summarized in Table 2. The first tag was the type of self-reinforcing mechanism (tags: coordination effect, complementarity effect, expectation effect or investment and learning effect), which was determined based on the definitions of each type as described in the theoretical framework. The second tag was the locus of mechanism, i.e. whether the repeated

\footnotetext{
2 This also allowed us to assume that the identified mechanisms would be recognised by most industry participants. Together with information gained through attendance at the industry conference (Strategies in Light Europe in Munich in 2012), the interviews confirmed that industry participants share the same basic view of technology development, market trends and challenges. The number of interviews was too limited to allow for a full account of the perceptions of all industry participants, but this limitation did not affect the purpose of this study as, by challenging the idea of lock-in, our definition of path dependency does not require all participants to think and act in the same way.
} 
pattern was related to technology adoption (tag: adoption) or technology development (tag: development). For example, several data sources suggested that incandescent lamps became an evaluation standard of a good lighting in the eyes of consumers. If the sources discussed how this led to consumer loyalty and a repeated choice by consumers to buy incandescent lamps, we would tag this as an adoption-related self-reinforcing mechanism. To the extent that this loyalty made manufacturers reproduce some characteristics of incandescent lamps in other technologies, we would also tag it as a development-related mechanism. The third tag was the direction of influence, i.e. if it occurred within one technology (tag: feedback) or across technologies (tag: externality). The fourth and final tag was the character of influence, i.e. if it reinforced the pattern (tag: positive) or weakened it (tag: negative).

The mechanisms and their tags were compared and discussed, after which a selection was made of a number of mechanisms that were to be discussed in more detail as examples in the article. This selection was made so that to represent different types of mechanisms.

Table 2. Tags for analysis of self-reinforcing mechanisms

\begin{tabular}{ll}
\hline Tag category & Available tags \\
\hline Type of self-reinforcing mechanism & Coordination effects \\
& Complementarity effects \\
& Expectation effects \\
& Investment and learning effects \\
\hline Locus of mechanism & Adoption \\
\hline Direction of influence & Development \\
& Feedback \\
\hline Character of influence & Externality \\
\hline
\end{tabular}

\section{Self-reinforcing mechanisms in the lighting industry}

\subsection{Technological paths in the lighting industry}

The electric lighting industry was established in the late $19^{\text {th }}$ century with the introduction of the incandescent bulb. In the course of the $20^{\text {th }}$ century, a number of other types of light 
sources appeared: halogen lamps, linear and compact fluorescent lamps (LFL and CFL), high pressure discharge lamps (including metal halide lamps, low and high pressure sodium lamps) and light emitting diodes (LED). Among them, only halogen lamps are a technological improvement of the incandescent lamps, while the others are completely different technologies. At the most general level, three lighting technologies can be identified: incandescent, discharge and LED. Within each of these, various technological trajectories can be distinguished, e.g. LFL and CFL as two trajectories within discharge lamps. The lighting industry is, thus, an example of a multi-technology industry characterized by the co-existence of multiple technological paths.

Among the three general-level lighting technologies, incandescent bulbs have the lowest purchase price and provide a warm light which is very close to daylight. They are not very energy efficient and have a relatively short service life. Discharge lamps are more energy efficient and have a longer service life compared with incandescent bulbs, but they are more expensive in terms of purchase price and generally provide a colder, bluish light. The latest lighting technology, LED, provides considerable improvements in terms of energy efficiency and service life and the miniature size of the light sources opens up for rich design possibilities. They are, however, still characterised by a very high purchase price compared with other lamp types.

Today, the lighting industry is characterized by a considerable push for more energy efficient lighting (Ashe et al. 2012), which recently has led to legislation in several countries aiming at phasing out the incandescent bulb. There is also an ongoing debate with regard to potential changes caused by the appearance of LED lamps (e.g., new business models building on integration between fixtures and light sources). 


\subsection{Examples of four types of self-reinforcing mechanisms in the lighting industry}

\subsubsection{Coordination effects}

Technology-internal coordination effects in the lighting industry can be seen in a higher availability of incandescent lamps in supermarkets, grocery stores, large department stores and furniture stores (IEA 2006), even after CFL and (later) LED lamps were introduced in the market (until the recent incandescent "ban” in some countries and regions). Since they were more available, incandescent lamps sold better which, in turn, was a reason for the stores to keep them more available. This adoption-related positive feedback of incandescent lamps was mirrored by a negative externality for newer technologies that could not reach end users to the same extent in spite of being present in the market.

Another technology-internal coordination effect can be seen in the development of CFL lamps that initially suffered from technical and customer acceptance issues. A crucial moment in overcoming these problems was the establishment of harmonized testing and performance specifications as a result of the CFL Harmonization Initiative (OECD/IEA 2010). Thus, once producers started following the same procedures for CFL testing and compliance, consumer acceptance improved which further legitimized the use of these harmonized procedures. This development-related positive feedback resulted in a negative externality for competing technologies as it improved the relative advantage of CFLs.

An example of a positive cross-technology coordination effect is the tendency of lamp manufacturers to copy the characteristics and performance of incandescent lamps when developing new technologies. This process is caused by strong customer preferences in favor of the characteristics of incandescent lighting, e.g. low purchase price and excellent color rendering, which have made incandescent lamps the "evaluation standard” to which other technologies are compared (Menanteau and Lefebvre 2000, IEA 2006). Due to the high 
legitimacy of incandescent lamps, other technologies are expected to provide the same performance attributes as incandescent lamps in order to be accepted by the market, even though they have their own distinct advantages (Menanteau and Lefebvre, 2000). ${ }^{3}$

Manufacturers therefore make efforts to overcome this problem by making new types of lamps similar to incandescent bulbs across a wide range of performance criteria. For example, CFL lamps have copied luminous flux values (Heidemann et al. 1993), color performance (LRC 2003) and the shape, size and aesthetics (ALG 2012) from incandescent bulbs. Most notably, manufacturers started to produce CFLs enclosed with a glass casing to resemble incandescent bulbs (Iwafune 2000). LEDs are also increasingly produced as retrofit lamps that copy the visual appearance of incandescent bulbs, in spite of the rich design possibilities that are available for them as a consequence of their semiconductor nature (including integrated lamp-fixture solutions (LEDs Magazine 2005)). The availability of an even wider range of lamps that look and perform like incandescent bulbs further strengthens existing customer preferences. This development-related externality is an example of how the development processes inherent to one technology (incandescent bulbs) result in similar development patterns in other technologies (LFL, CFL and LED) (and back again). It, thus, gives a positive influence across technologies as the development pattern is repeated rather than weakened. This kind of positive externality clearly goes beyond the logic of positive feedbacks and negative externalities described in previous literature.

\subsubsection{Complementarity effects}

With regard to technology-internal complementarity effects, technology adoption is characterized by a durability of lighting fixtures, which have much longer service lives than the light sources themselves. The importance of existing fixtures is further highlighted by the

\footnotetext{
${ }^{3}$ Initially, this held back the diffusion of LFLs, CFLs and LED, which could be interpreted as an adoptionrelated negative externality (cf. Sathaye and Murtishaw 2004, Menanteau and Lefebvre 2000, Babcock 2009).
} 
character of the lighting market, where over $90 \%$ of the sales of leading manufacturers come from the replacement of existing lamps (Stettler, Leslie, and Bell 2010) . Therefore, users are to a large extent locked in to using the same type of lamp until they replace their existing fixtures (IEA 2006) and there are few incentives to replace fixtures as long as there are lamps that fit into them. When customers have adopted a particular type of fixture they are therefore likely to continue to adopt the same type of lamp over and over again (positive feedback for that technology), which implies a negative externality for other lamp technologies. For example, the diffusion of linear fluorescent tubes (LFLs) and halogen lamps was slowed down because they used other fittings than incandescent bulbs and therefore required other fixtures and early CFLs were too long and "bulky" to fit into luminaires designed to match the standard dimensions of incandescent bulbs (Martinot and Borg 1998, IEA 2006, Menanteau and Lefebvre 2000). The same type of problems currently exists for LED as well, although not only with regard to incandescent bulbs but also to halogen lamps (spotlights) (cf. Hedekvist 2011). ${ }^{4}$

The durability of fixtures has also resulted in cross-technology complementarity effects related to technology development. As mentioned above, newer lamp technologies, e.g. CFL and LED, initially had low sales because they were incompatible with existing fixtures. Instead of just accepting this negative externality, lamp manufacturers responded by miniaturizing newer lamps to make them fit into existing fixtures (Weiss, Junginger, and Patel 2008, IEA 2006, Iwafune 2000, Sathaye and Murtishaw 2004). For CFLs, the introduction of amalgam technology was key to reducing size (VITO 2009). Manufacturers also developed new CFL lamps with screw-based sockets, which were compatible with existing fixtures (in contrast to the pin-based sockets that were used initially). This mechanism shows that a

\footnotetext{
${ }^{4}$ The same mechanism can also occur within technological paths. For example, the T5 LFL tube does not fit into fixtures developed for earlier LFLs (the T12 and T8 tubes) and this has slowed down adoption of T5s (IEA 2006).
} 
complementary resource associated with one technology can be used by newer technologies as soon as they are adapted, which in turn reinforces the value of the complementary resource and provides further incentives to adapt to them. This is another evidence of positive interaction across technologies: by repeating an established development pattern to make sure that newer lamp technologies can use the same fixtures as older technologies, a synergy is created from which both incandescent and the adapted light sources can benefit.

\subsubsection{Expectation effects}

A technology-internal expectation effect related to technology adoption is seen in the sustained loyalty to the incandescent bulb because it is well-known or because it is the evaluation standard to which other technologies are compared (Babcock 2009, IEA 2006). For example, consumers are used to selecting lamps based on the purchase price and performance characteristics of incandescent bulbs (Babcock 2009). For example, they tend to compare lamp prices based on purchase prices rather than total service life costs, which works to the disadvantage of CFLs and LEDs as they are much more expensive at first but have lower operating costs (which is not well understood by consumers) (IEA 2006). A corresponding self-reinforcing mechanism for CFL lamps was not initiated when they were first introduced since the new technology failed to meet customers’ expectations. However, a number of demand-side management campaigns in different countries, such as rebate coupons and giveaway programs (Iwafune 2000), eventually stimulated the emergence of an adoption-related positive feedback in terms of an increasing loyalty to CFL lamps. Because of the incentives, consumers started to buy CFL lamps and through this gained more information about the technology and the risks associated with it, which in turn induced further adoption (Menanteau and Lefebvre 2000). In both these examples, positive feedbacks created mirror negative externalities for all other, competing technologies. 
Another technology-internal expectation effect can be seen in the gradual advance of LED technology since the 1960s through the exploitation of a series of market niches. Indicator lights, traffic lights, exit signs and architectural lighting are some examples of applications that served as intermediary steps helping LED scale up to the level of general lighting (Sanderson and Simons 2014). In this self-reinforcing mechanism, each new application contributed to creating a "see-saw dynamic between technological advance pulled by the promise of new markets, and the opening of new markets pushed by technological advance” (Haitz and Tsao, 2003 in Sanderson et al. 2008, p. 1739). This development-related positive feedback also created a negative externality for other lighting technologies that were previously used in corresponding applications and had to face an increasing competition.

Cross-technology expectation effects manifest themselves for example as a sustained ambition in the lighting industry to increase energy efficiency, which was initiated while developing incandescent lamps and further reproduced for every new lighting technology. This is shown by two development trends (see Table 3). On the one hand, new technologies have tended to be more energy efficient than previous ones (see Column 2), and have also been positioned as potential substitutes for incandescent bulbs (e.g. Burgin and Edwards 1970). On the other hand, gradual improvements in energy efficiency have also been achieved over time within each technology (compare Columns 2 and 3 in Table 3).

Table 3. Energy efficiency of light sources in the XX century.

\begin{tabular}{lcc}
\hline Technology & $\begin{array}{c}\text { Initial energy efficiency } \\
(\operatorname{lm} / \mathrm{W})\end{array}$ & $\begin{array}{c}\text { Recent energy efficiency } \\
(\operatorname{lm} / \mathrm{W})\end{array}$ \\
\hline Incandescent & 1.4 (late XIX century) & $18(2010)$ \\
LFL & $25-30(1940)$ & $89.5(2010)$ \\
CFL & $43-48(1990)$ & $55-60(2012)$ \\
LED & $3-30(2001)$ & $200(2013)$
\end{tabular}

Sources: Elaboration on Ashe et al. (2012), BBC (2013), Edwards (1972), Heanly (1982), IEA (2006), Menanteau and Lefebvre (2000), Navigant Consulting (2012) and Scholand and Dillon (2012). 
These two trends could be seen as a natural development trajectory of the industry, but a closer analysis suggests that a different kind of logic is behind this process. First, energy efficiency is only the most critical performance issue for incandescent bulbs. Other technologies had their own problems, for example flickering and modulation (fluorescent lighting) (Bruxdrett, Grifft, and Boyce 1973, Wilkins and Clark 1990, Veitch and McColl 1995, Berman et al. 1997) and color rendering (LEDs) (Sándor and Schanda 2006, Szabó, Bodrogi, and Schanda 2009, Pousset, Rougié, and Razet 2010, Alvi et al. 2011, Smet et al. 2012). Second, improved energy efficiency was not what the consumers asked for; the pressure to increase energy efficiency instead came mainly from policy in the form of investments in research of more efficient lighting technologies, new regulations (e.g. the ban of incandescent lamps) and public awareness campaigns (Ashe et al. 2012). New technologies, therefore, had to copy the performance attributes of incandescent lamps even though they had better energy efficiency characteristics. Third and finally, the theoretical efficacy limit of white light (approx. $250 \mathrm{~lm} / \mathrm{W}$ ) has been known for a long time (Willoughby 1974), which from a pragmatic point of view should have warned the industry that even if improvements would be made with regard to energy efficiency, there would still be a clear technological "ceiling” that could not be overcome without compromising color differentiation.

The sustained focus on energy efficiency in the lighting industry is, thus, not the result of a natural technology-push or market-pull dynamics, but rather a self-reinforcing mechanism. A development pattern was reproduced largely because of a technological weakness specifically associated with the incandescent bulb, which was targeted by policy pressures in favor of more energy efficiency lighting and further reinforced as all other technologies started to achieve higher levels of energy efficiency. The existence of a common development pattern 
across a number of technologies again shows the possibility of non-negative technology interaction, i.e. positive externalities.

\subsubsection{Investment and learning effects}

Technology-internal investment and learning effects related to technology adoption can be seen in the form of economies of scale and experience that have existed for incandescent lamps throughout the $20^{\text {th }}$ century. These have given incandescent bulbs a competitive advantage in terms of lower production costs and, consequently, higher adoption rates than other technologies, which in turn creates further learning effects (i.e. a positive feedback with a negative externality for other technologies). However, newer technologies have their own learning effects. Studies of CFL cost dynamics show learning rates of roughly 10-20 percent for CFLs (Weiss et al. 2010), and an even higher speed of cost and performance improvement (20-25 percent) can be seen for LEDs (Gould and Cheng 2011).

With regard to technology development, technology-internal investment effects are seen in the form of the sunk cost of large facilities that are quite specialized for each lamp type. For example, incandescent (and discharge) lamp manufacturing involves a process technology that requires specialized equipment, while LED lamp manufacturing is to a large extent based on an electronic assembly technology which implies a crucial difference with respect to production facilities required. For all technologies, there is a need to build large from the start to be able to produce at scale, so a new plant incurs substantial costs (Gould and Cheng, 2011). Once an investment in advanced manufacturing equipment for one lamp technology has been made, it therefore tends to be exploited to the full extent and new investments tend 
to be made to support rather than replace it. ${ }^{5}$ This implies positive feedbacks for technologies manufactured in existing plants, with a mirror negative externality for other technologies.

Cross-technology learning effects related to technology development are demonstrated by “development loops” between different lighting technologies. For example, patent data show an intense cross-referencing between the main patent classes associated with incandescent bulbs and discharge lamps respectively. The cross-referencing pattern between these two lighting technologies shows that technological activities can go forth and back between them several times within the same reference chain. ${ }^{6}$ This is an indicator of mutual learning across the two technologies, where the technological advances initiated in incandescent lighting continue in discharge lighting, after which the results are further used in incandescent lighting and so forth. Thus, this is one more example that shows that cross-path interactions (externalities) are not necessarily negative, since a common and repeated pattern of activities (technology development based on the same patents) is seen for both involved technologies.

\subsection{Summary analysis}

Our first research question was what kind of self-reinforcing mechanisms can be present in a multi-technology industry. The empirical analysis shows that all four types of self-reinforcing mechanisms mentioned in the previous literature have also been present in the lighting industry (see Table 4). We can thus confirm our suggestion that self-reinforcing mechanisms can and do exist also in multi-technology industries such as lighting, in spite of the fact that

\footnotetext{
${ }^{5}$ In addition, closing down existing plants is also associated with high costs; for example, following the shift from incandescent bulbs to CFLs Philips Lighting closed 13 of its 20 incandescent bulb factories in the period of 2001-2009 (Provoost 2009) and spent 500 million Euro between 2008 and 2010 on restructuring its production facilities (Stettler, Leslie, and Bell 2010).

${ }^{6}$ Below are several examples of such cross-reference patters, from the latest to the earliest patent. In parentheses, the first patent class is mentioned: H01J corresponds to discharge lighting and $\mathrm{H} 01 \mathrm{~K}$ to incandescent lighting:

a) $8,471,445(\mathrm{H} 01 \mathrm{~J})->5,905,343(\mathrm{H} 01 \mathrm{~K})->4,311,942(\mathrm{H} 01 \mathrm{~J})$

b) $4,908,546(\mathrm{H} 01 \mathrm{~J})->4,015,165(\mathrm{H} 01 \mathrm{~K})->3,818,558(\mathrm{H} 01 \mathrm{~J})->2,987,696(\mathrm{H} 01 \mathrm{~K})$

c) $6,563,267(\mathrm{H01J})->5,698,946(\mathrm{H} 01 \mathrm{~K})->5,021,711(\mathrm{H} 01 \mathrm{~J})->4,015,165(\mathrm{H} 01 \mathrm{~K})$

d) $8,193,710(\mathrm{H} 01 \mathrm{~J})->7,095,175(\mathrm{H} 01 \mathrm{~K})->5,021,711(\mathrm{H} 01 \mathrm{~J})->4,015,165(\mathrm{H} 01 \mathrm{~K})$

e) $8,102,109(\mathrm{H} 01 \mathrm{~K})$-> 5,281,889 (H01J) -> 4,119,877 (H01K) -> 4,013,335 (H01J) -> 3,739,221 (H01K)
} 
there is no technological lock-in to a single path. We can also confirm that the typology suggested in the previous literature is useful for identifying and categorizing them.

As in previous literature (e.g. Pierson 2000, Dobusch and Schüßler 2012), we found technology-internal positive feedbacks for several of the lighting technologies. Some of these were adoption-related mechanisms (e.g. availability in stores and durability of fixtures) that resulted in repeated decisions by customers to adopt a particular technology - in this case primarily incandescent bulbs - whereas other positive feedbacks were development-related (e.g. sunk costs) and resulted in repeated decisions by manufacturers to develop a certain technology or specific performance characteristics. As described in previous literature (e.g. Vergne and Durand 2010), positive feedbacks within one technology were reflected by crosstechnology negative externalities for other lamp technologies.

However, in contrast to previous literature on path dependency, we found self-reinforcing mechanisms that had the character of positive influences across technologies and therefore could be described as positive externalities. These resulted in a repeated pattern of development of features primarily associated with incandescent bulbs, but “inherited” by later lamp technologies, which further strengthened the incandescent bulb’s status as an evaluation standard. Interestingly, these positive externalities were related primarily to technology development rather than to technology adoption. This shows the importance of explicitly considering development-related mechanisms in order not to leave out crucial aspects of cross-path interactions. Moreover, examples of positive externalities were found that represented all the four types of self-reinforcing mechanism described in previous literature. Our study has, thus, expanded the existing empirical evidence of self-reinforcing mechanisms (cf. Araujo and Harrison 2002, Sydow, Schreyögg, and Koch 2009, Sydow et al. 2012, Dobusch and Schüßler 2012). 
Table 4. Examples of self-reinforcing mechanisms in the lighting industry.

\begin{tabular}{|c|c|c|c|c|}
\hline Type of SRM & Mechanism & $\begin{array}{l}\text { Technology- } \\
\text { internal influence }\end{array}$ & $\begin{array}{l}\text { Cross-technology } \\
\text { influence }{ }^{\mathrm{a}}\end{array}$ & $\begin{array}{l}\text { Development vs. } \\
\text { adoption }\end{array}$ \\
\hline \multirow[t]{3}{*}{$\begin{array}{l}\text { Coordination } \\
\text { effects }\end{array}$} & $\begin{array}{l}\text { Availability in } \\
\text { stores of } \\
\text { incandescent }\end{array}$ & PF (incandescent) & $\begin{array}{l}\text { NE (all other } \\
\text { technologies) }\end{array}$ & Adoption \\
\hline & $\begin{array}{l}\text { Following } \\
\text { harmonized } \\
\text { testing and } \\
\text { performance } \\
\text { specifications for } \\
\text { CFL lamps }\end{array}$ & PF (CFL) & $\begin{array}{l}\text { NE (all other } \\
\text { technologies) }\end{array}$ & Development \\
\hline & $\begin{array}{l}\text { Adaptation of } \\
\text { technologies to } \\
\text { imitate } \\
\text { incandescent }\end{array}$ & - & $\begin{array}{l}\text { PE (incandescent } \\
\text { and adapted } \\
\text { technologies) }\end{array}$ & Development \\
\hline \multirow[t]{2}{*}{$\begin{array}{l}\text { Complementarity } \\
\text { effects }\end{array}$} & $\begin{array}{l}\text { Durability of } \\
\text { lighting fixtures }\end{array}$ & $\begin{array}{l}\text { PF (incandescent } \\
\text { and other } \\
\text { technologies that } \\
\text { fit existing } \\
\text { fixtures) }\end{array}$ & $\begin{array}{l}\text { NE (all other } \\
\text { technologies) }\end{array}$ & Adoption \\
\hline & $\begin{array}{l}\text { Adaptation of } \\
\text { technologies to fit } \\
\text { existing fixtures }\end{array}$ & - & $\begin{array}{l}\text { PE (incandescent } \\
\text { and adapted } \\
\text { technologies) }\end{array}$ & Development \\
\hline \multirow[t]{4}{*}{$\begin{array}{l}\text { Expectations } \\
\text { effects }\end{array}$} & $\begin{array}{l}\text { Loyalty to } \\
\text { incandescent }\end{array}$ & PF (incandescent) & $\begin{array}{l}\text { NE (all other } \\
\text { technologies) }\end{array}$ & Adoption \\
\hline & $\begin{array}{l}\text { Loyalty to CFL } \\
\text { after demand- } \\
\text { sede management } \\
\text { programs }\end{array}$ & PF (CFL) & $\begin{array}{l}\text { NE (all other } \\
\text { technologies) }\end{array}$ & Adoption \\
\hline & $\begin{array}{l}\text { See-saw effects } \\
\text { during LED } \\
\text { advancement } \\
\text { across a number } \\
\text { of market niches }\end{array}$ & PF (LED) & $\begin{array}{l}\text { NE (all other } \\
\text { technologies) }\end{array}$ & Development \\
\hline & $\begin{array}{l}\text { Sustained strive } \\
\text { to improve } \\
\text { energy efficiency }\end{array}$ & - & $\begin{array}{l}\text { PE (incandescent } \\
\text { and all other } \\
\text { technologies) }\end{array}$ & Development \\
\hline \multirow[t]{3}{*}{$\begin{array}{l}\text { Investment and } \\
\text { learning effects }\end{array}$} & $\begin{array}{l}\text { Economies of } \\
\text { scale }\end{array}$ & $\begin{array}{l}\text { PF (separate for } \\
\text { each technology) }\end{array}$ & $\begin{array}{l}\text { NE (all other } \\
\text { technologies) }\end{array}$ & Adoption \\
\hline & Sunk costs & $\begin{array}{l}\text { PF (separate for } \\
\text { each technology) }\end{array}$ & $\begin{array}{l}\text { NE (all other } \\
\text { technologies) }\end{array}$ & Development \\
\hline & $\begin{array}{l}\text { Cross-technology } \\
\text { learning }\end{array}$ & - & $\begin{array}{l}\text { PE (all involved } \\
\text { technologies) }\end{array}$ & Development \\
\hline
\end{tabular}

${ }^{\text {aPF }}$ - positive feedback. NE - negative externality. PE - positive externality. 
The existence of both negative and positive externalities also holds part of the answer to our second research question, i.e. the role of self-reinforcing mechanisms in enabling the survival of several alternative technologies and avoiding technological lock-in to one single path. Whereas previous literature has shown that self-reinforcing mechanisms at different levels can interact with each other to drive a path forward (cf. interaction between local and populationlevel mechanisms as discussed by Dobusch and Schüßler (2012)), our empirical study shows that mutual reinforcements can take place also across different pats, i.e. that paths can have positive as well as negative influences on each other.

Whereas negative cross-path influences in the form of negative externalities have been discussed in previous path dependency literature (e.g. Page 2006, Vergne and Durand 2010), the existence of positive externalities has not been explicitly acknowledged there. The existence of positive externalities suggests that one reason why co-existing paths do not outcompete each other in multi-technology industries is that positive developments in one technology spills over to other technologies. Adding this perspective de-emphasizes technology competition and instead recognizes the advantages of potential synergies in terms of, e.g., shared resources. This implies that even when two (or more) technologies compete in the same market, their relationship is not necessarily purely competitive but can also involve elements of symbiosis or commensalism (cf. Hillman and Sandén 2008). Because of this, we suggest that positive externalities have the potential to (partly) balance out negative externalities mirroring the positive feedbacks associated with established paths (as in the case of the incandescent bulb), which allows new technological paths (such as CFL or LED) to emerge without outcompeting (or being outcompeted by) the established path.

It should be noted here that the term "positive” does not necessarily imply that all the interacting technologies are successful in the market. It is positive in the sense that it leads to a repeated pattern, i.e. experience acquired within one technology is reused in other 
technologies, but this pattern might in fact be detrimental to the further development or diffusion of one or all of the interacting technologies. For example, a decision to allocate resources to developing a particular feature of the technology might lead to the identification of new technical problems, which in turn leads to new decisions to allocate resources to the same line of development, but this does not necessarily mean that the technical problems will ever be solved or that the new feature will be valued in the market. However, when adoptionrelated self-reinforcing mechanisms are concerned, positive mechanisms imply repeated adoption decisions and, thus, also some kind of success for the technology in question.

We might illustrate these additions to previous path dependency theory by means of a two-bytwo matrix, where we distinguish between four categories of self-reinforcing mechanisms based on the type of whether the character of influence is positive or negative and whether the direction of influence is technology-internal or cross-technology (see Figure 1). To repeat some definitions made previously, positive mechanisms reinforce the pattern of adoption or development whereas negative mechanisms weaken that pattern. Technology-internal mechanisms (feedbacks) imply that developments in one technology influence future developments in that technology, whereas cross-technology mechanisms (externalities) imply that developments in one technology influence future developments in other technologies.

\begin{tabular}{|c|c|c|c|}
\hline \multirow{3}{*}{$\begin{array}{l}\text { Character of } \\
\text { influence }\end{array}$} & $\begin{array}{l}\text { Positive (reinforced } \\
\text { pattern) }\end{array}$ & $\begin{array}{l}\text { Positive } \\
\text { feedbacks }\end{array}$ & $\begin{array}{c}\text { Positive } \\
\text { externalities }\end{array}$ \\
\hline & $\begin{array}{l}\text { Negative (weakened } \\
\text { pattern) }\end{array}$ & $\begin{array}{l}\text { Negative } \\
\text { feedbacks }\end{array}$ & $\begin{array}{c}\text { Negative } \\
\text { externalities }\end{array}$ \\
\hline & & $\begin{array}{l}\text { Technology- } \\
\text { internal } \\
\text { mechanisms }\end{array}$ & $\begin{array}{c}\text { Cross- } \\
\text { technology } \\
\text { mechanisms }\end{array}$ \\
\hline
\end{tabular}

Figure 1: Four categories of self-reinforcing mechanisms 
As mentioned above, we found evidence in our empirical study of positive feedbacks, negative externalities and positive externalities. The existence of negative feedbacks seems logic from a theoretical point of view, but could not be fully confirmed in our study. We did, however, find some indications of negative feedbacks in the case of CFL. When first introduced, CFL lamps suffered from a number of quality issues, such as flickering, noise, long warm-up times and bluish light, which harmed reputation of this technology (IEA 2006). Further, when large producers had solved these issues, CFL technology attracted low-cost manufacturers that started selling, again, low-quality products, which, given previous quality problems, reinforced a negative image of CFLs in the eyes of consumers (OECD/IEA 2010). Thus, a negative pattern was repeated which led to a long and complicated market penetration process. In the case of CFL, both quality and legitimacy issues were addressed with the help of demand-side management programs and testing procedures (OECD/IEA 2010, IEA 2006), but this example shows that failure of some technologies can be explained in terms of path dependency, though not through positive feedbacks and negative externalities related to established technologies, but through negative feedbacks related to a new technology. That is a topic for further research as well as a question whether such negative feedbacks are reflected in the form of positive externalities on the remaining alternatives (in the same way as positive feedbacks are usually reflected on other technologies in the form of negative externalities).

Another interesting topic for further research is the role of agency in establishing positive externalities, especially to the extent it concerns technology development. On the one hand, our findings support the perspective that actors are able to strategically manage selfreinforcing mechanisms (Garud, Kumaraswamy, and Karnøe 2010). For example, the lamp manufacturers very deliberately adapted new technologies to mimic the incandescent bulb in order for them to benefit from existing positive feedback mechanisms. Thus, this might 
suggest that development-related self-reinforcing mechanisms are at least partly the result of conscious efforts of actors. On the other hand, manufacturers are not entirely free in choosing their course of actions. For example, the decision to adapt later technologies to mimic incandescent lamps was both caused by path dependency at the adoption side and further reinforced some of the previously existing mechanisms. Therefore, distinguishing pathbreaking choices of actors from path dependent ones requires careful consideration and further empirical investigation.

\section{Conclusions}

The purpose of this paper was to investigate what kind of self-reinforcing mechanisms can be present in multi-technology industries and explain how paths can co-exist and interact in a context of self-reinforcement and, ultimately, path dependency. Through a historical study of the lighting industry, we have shown that the four types of self-reinforcing mechanisms that were described in the previous literature, i.e. coordination effects, complementarity effects, expectation effects and investment and learning effects, can also be found in multi-technology industries. We have also contributed to previous path dependency literature by explicitly distinguishingbetween self-reinforcing mechanisms related to technology adoption and technology development respectively and by doing so we have highlighted that selfreinforcement can characterize both technology users and suppliers. Further, we have provided examples of technology-internal positive feedbacks as well as cross-technology externalities.

Whereas the previous findings apply to all types of industries, the main contribution of this paper is that it captures additional processes that seem to be specific to multi-technology industries, i.e. the existence of positive cross-technology externalities. While the previous literature has considered negative externalities as the only possible form of technology 
interaction, in this study we have provided evidence of positive interaction between technologies. Because of these positive externalities, the same technology development patterns were reproduced across technologies, which is why advancements in one technology could contribute to corresponding advancements in other technologies.

An implication of this is that multi-technology industries can be path dependent - even though they are not locked in to one technology but rather characterized by the co-existence of several technologies. Indeed, our analysis suggests that their multi-technology character is partly due to cross-technology self-reinforcing mechanisms in the form of positive externalities, which create a symbiotic relationship between technologies and make it possible for several technologies to survive and co-exist even in a context of path dependency. One might even go as far as saying that multi-technology industries are able to be innovative and add new technologies to already existing ones not in spite of path dependency, but, at least partly, because of path dependency.

This indicates that positive externalities at least to some extent are beneficial for the development of established industries. They make it possible to sustain a certain technology variety and prevent lock-in to (inferior) technologies. According to the evolutionary theory of technical change, this is positive for innovation (and, in consequence, for economic development), since it creates conditions for new combinations and resource synergies to occur (cf. Carlsson and Eliasson 2003). However, some of the positive externalities found in the lighting industry were due to manufactures’ imitating the characteristics and performance of the dominant design (the incandescent bulb) when developing new technologies. If this is a more general phenomenon, positive externalities might prevent more disruptive innovations (e.g. integrated LED solutions) from gaining a foothold in the industry, which in the long run 
might have detrimental effects on industrial development and growth and might prevent an industry from fully exploiting the potential of new technologies ${ }^{7}$.

With regard to potential benefits of positive externalities and sustained technological variety, an interesting question for further research is what enables such non-competitive technology interactions to occur. Based on the evidence from the lighting industry, we can suggest that one possible answer might be the existence of a large number of lighting applications that prioritize different performance criteria (cf. Menanteau and Lefebvre 2000). Furthermore, leading industry actors tend to have a broad portfolio of technologies they produce as well as applications they serve which contributes to an environment where potential cross-technology spillovers are encouraged while lock-in can be avoided. However, a comprehensive analysis of preconditions for positive externalities requires further investigation that involves crossindustry comparisons.

\section{Acknowledgements}

Comments from two anonymous reviewers are gratefully acknowledged. The study on which this article is based was partially funded by Riksbankens Jubileumsfond via the KITE research program.

\section{References}

ALG. 2012. "Evolution of the Incandescent Lamp." ALG Connections.

Alvi, NH, K. ul Hasan, O. Nur, and M. Willander. 2011. "The effect of post-growth annealing on the colour properties of $\mathrm{n}-\mathrm{ZnO}$ nanorods/p-GaN white LEDs." Lighting Research and Technology 43 (3):331-336. doi: 10.1177/1477153511398025.

Antonelli, C. 2009. "The economics of innovation: From the classical legacies to the economics of complexity." Economics of Innovation and New Technology 18 (7):611-646.

Araujo, Luis, and Debbie Harrison. 2002. "Path Dependence, Agency and Technological Evolution." Technology Analysis \& Strategic Management 14 (1):5-19.

\footnotetext{
${ }^{7}$ One might suggest that the lighting industry could be locked in to three paths, much in the same way as regions or countries can be locked in to a particular configuration of industrial specialization (Martin and Sunley 2006). Although this is a theoretical possibility, the emergence of LED as a new lighting technology, which builds on (and interacts with) previous older technologies but is based on a fundamentally different lighting principle, speaks against an overall lock-in in this case.
} 
Arrow, Kenneth J. 1962. "The Economic Implications of Learning by Doing." The Review of Economic Studies 29 (3):155-173. doi: 10.2307/2295952.

Arthur, W Brian. 1994. Increasing returns and path dependence in the economy: University of Michigan Press.

Arthur, W. Brian. 1989. "Competing Technologies, Increasing Returns, and Lock-In by Historical Events." The Economic Journal 99 (394):116-131.

Arthur, W. Brian. 1996. "Increasing Returns and the New World of Business." Harvard Business Review (July-August):100-109.

Ashe, M., D. Chwastyk, C. de Monasterio, M. Gupta, and M. Pegors. 2012. 2010 U.S. Lighting Market Characterization. Washington DC.: U.S. Department of Energy, Office of Energy Efficiency and Renewable Energy.

Babcock, Hope M. 2009. "Responsible Environmental Behavior, Energy Conservation, and Compact Fluorescent Bulbs: You Can Lead a Horse to Water But Can You Make It Drink?" Hofstra Law Review 37 (4).

BBC. 2013. "'Most energy-efficient' LED light revealed by Philips." BBC, Last Modified 20130411 Accessed 20130807. http://www.bbc.co.uk/news/technology-22106718.

Bergek, Anna, and Ksenia Onufrey. 2014. "Is one path enough? Multiple paths and path interaction as an extension of path dependency theory." Industrial and Corporate Change 23 (5):12611297.

Berman, S.M., Blaine R Benson, Jennifer A Veitch, and Shelley L McColl. 1997. "Modulation of fluorescent light: Flicker rate and light source effects on visual performance and visual comfort." Lighting Research and Technology 29 (1):54-56. doi: 10.1177/14771535970290010401.

Bollinger, Bryan, and Kenneth Gillingham. 2012. "Peer Effects in the Diffusion of Solar Photovoltaic Panels." Marketing Science 31 (6):900-912. doi: 10.1287/mksc.1120.0727.

Bruxdrett, G.W., L.D. Grifft, and P.R. Boyce. 1973. "Subjective response to a.c. and d.c. fluorescent lighting." Lighting Research and Technology 5 (3):160-162. doi: 10.1177/096032717300500304.

Burgin, R., and E.F. Edwards. 1970. "The tungsten halogen lamp decade." Lighting Research and Technology 2 (2):95-108. doi: 10.1177/14771535700020020901.

Carlsson, B., and G. Eliasson. 2003. "Industrial dynamics and endogenous growth." Industry and Innovation 10 (4):435-456.

Cecere, Grazia. 2009. "VoIP Diffusion among New Entrants: A Path Dependent Process." Industry and Innovation 16 (2):219-245. doi: 10.1080/13662710902764410.

Christensen, Clayton M., and Joseph L. Bower. 1996. "Customer power, strategic investment, and the failure of leading firms." Strategic Management Journal 17 (3):197-218. doi: 10.1002/(sici)1097-0266(199603)17:3<197::aid-smj804>3.0.co;2-u.

Cowan, Robin. 1990. "Nuclear Power Reactors: A Study in Technological Lock-in." The Journal of Economic History 50 (3):541-567.

Cowan, Robin, and Philip Gunby. 1996. "Sprayed to Death: Path Dependence, Lock-in and Pest Control Strategies." The Economic Journal 106 (436):521-542.

David, Paul A. 1985. "Clio and the Economics of QWERTY." The American Economic Review 75 (2):332-337.

DiMaggio, Paul J., and Walter W. Powell. 1983. "The Iron Cage Revisited: Institutional Isomorphism and Collective Rationality in Organizational Fields." American Sociological Review 48 (2):147160.

Dobusch, Leonhard, and Jakob Kapeller. 2013. "Breaking New Paths: Theory and Method in Path Dependence Research." Schmalenbach Business Review 65 (July):288-311.

Dobusch, Leonhard, and Elke Schüßler. 2012. "Theorizing path dependence: a review of positive feedback mechanisms in technology markets, regional clusters, and organizations." Industrial and Corporate Change. doi: 10.1093/icc/dts029. 
Dosi, Giovanni. 1982. "Technological paradigms and technological trajectories: A suggested interpretation of the determinants and directions of technical change." Research Policy 11 (3):147-162. doi: 10.1016/0048-7333(82)90016-6.

Edwards, E.F. 1972. "Discharge lamps: some aspects of research and development." Lighting Research and Technology 4 (3):117-128. doi: 10.1177/096032717200400301.

Fai, Felicia M. 2003. Corporate Technological Competence and the Evolution of Technological Diversification. Cheltenham: Edward Elgar.

Farrell, Joseph, and Garth Saloner. 1985. "Standardization, Compatibility, and Innovation." The RAND Journal of Economics 16 (1):70-83. doi: 10.2307/2555589.

Foray, Dominique. 1997. "The dynamic implications of increasing returns: Technological change and path dependent inefficiency." International Journal of Industrial Organization 15 (6):733752.

Garud, R., A. Kumaraswamy, and P. Karnøe. 2010. "Path dependence or path creation?" Journal of Management Studies 47 (4):760-774.

Gould, Josh, and David Cheng. 2011. Advanced Lighting Market Insight: Overview \& Segmentation Analysis. San Francisco: Cleantech Gruop.

Granstrand, Ove, Pari Patel, and Keith Pavitt. 1997. "Multi-Technology Corporations: Why They Have "Distributed" Rather Than "Distinctive Core" Competencies." California Management Review 39 (4 (summer)):8-25.

Granstrand, Ove, and Sören Sjölander. 1990. "Managing innovation in multi-technology corporations." Research Policy 19 (1):35-60. doi: 10.1016/0048-7333(90)90033-3.

Grant, Robert M. 1991. "The Resource-Based Theory of Competitive Advantage: Implications for Strategy Formulation." California Management Review 33 (3):114-135.

Heanly, M.A.C. 1982. "Book Reviews: Light Source Technology, IEE Proceedings A Volume 27, Institution of Electrical Engineers, f12.00." Lighting Research and Technology 14 (1):47-48. doi: 10.1177/096032718201400104.

Hedekvist, Per Olof. 2011. "LED som ersättning för spotlights." Ceebel Nyhetsbrev, 1.

Heidemann, A., S. Hien, E. Panofski, and U. Roll. 1993. "Compact fluorescent lamps." Science, Measurement and Technology, IEE Proceedings A 140 (6):429-434.

Henderson, Rebecca M., and Kim B. Clark. 1990. "Architectural Innovation: The Reconfiguration of Existing Product Technologies and the Failure of Established Firms." Administrative Science Quarterly 35:9-30.

Hillman, K. M., and B. A. Sandén. 2008. "Exploring technology paths: The development of alternative transport fuels in Sweden 2007-2020." Technological Forecasting and Social Change 75 (8):1279-1302.

IEA. 2006. Light's Labour's Lost. Policies for Energy-efficient Lighting. Paris Cedex: OECD/IEA.

Iwafune, Yumiko. 2000. Technology Progress Dynamics of Compact Fluorescent Lamps. Laxenburg: International Institute for Applied Systems Analysis.

Katz, Michael L, and Carl Shapiro. 1985. "Network externalities, competition, and compatibility." The American economic review:424-440.

Kay, N. M. 2013. "Rerun the tape of history and QWERTY always wins." Research Policy 42 (67):1175-1185.

Koch, Jochen, Martin Eisend, and Arne Petermann. 2009. "Path dependence in decision-making processes: Exploring the impact of complexity under increasing returns." BuR-Business Research 2 (1):67-84.

LEDs Magazine. 2005. "Escaping the bulb culture: the future of LEDs in architectural illumination." LEDs Magazine, April 2005.

Liebowitz, S. J., and S. E. Margolis. 1995. "Path dependence, lock-in, and history." Journal of Law, Economics, and Organization 11 (1):205-226.

LRC. 2003. Increasing Market Acceptance of Compact Fluorescent Lamps (CFL). Troy: Lighting Research Center, Rensselaer Polytechnic Institute. 
Mahoney, James. 2000. "Path Dependence in Historical Sociology." Theory and Society 29 (4):507548.

March, James G. 1991. "Exploration and Exploitation in Organizational Learning." Organization Science 2 (1):71-87. doi: doi:10.1287/orsc.2.1.71.

Martin, R., and P. Sunley. 2006. "Path dependence and regional economic evolution." Journal of Economic Geography 6 (4):395-437.

Martinot, Eric, and Nils Borg. 1998. "Energy-efficient lighting programs: Experience and lessons from eight countries." Energy Policy 26 (14):1071-1081. doi: http://dx.doi.org/10.1016/S03014215(98)00052-4.

Mazzoleni, R. 1997. "Learning and path-dependence in the diffusion of innovations: Comparative evidence on numerically controlled machine tools." Research Policy 26 (4-5):403-428.

Menanteau, Philippe, and Hervé Lefebvre. 2000. "Competing technologies and the diffusion of innovations: the emergence of energy-efficient lamps in the residential sector." Research Policy 29 (3):375-389. doi: 10.1016/s0048-7333(99)00038-4.

Navigant Consulting Inc. 2012. Life-Cycle Assessment of Energy and Environmental Impacts of LED Lighting Products. Part I: Review of the Life-Cycle Energy Consumption of Incandescent, Compact Fluorescent, and LED Lamps. Washington DC: U.S. Department of Energy, Office of Energy Efficiency and Renewable Energy.

OECD/IEA. 2010. Transforming global markets for clean energy products. Energy efficient equipment, vehicles and solar photovoltaics. Paris Cedex: International Energy Agency.

Onufrey, Ksenia. 2014. "Technology dynamics in multi-technology industries: selection and variety creation through the lens of path dependency and path generation." Licentiate of Engineering Compilation thesis, Department of Management and Engineering, Linköping University.

Page, Scott E. 2006. "Path dependence." Quarterly Journal of Political Science 1 (1):87-115.

Pierson, Paul. 2000. "Increasing returns, path dependence, and the study of politics." American political science review:251-267.

Pousset, N., B. Rougié, and A. Razet. 2010. "Impact of current supply on LED colour." Lighting Research and Technology 42 (4):371-383. doi: 10.1177/1477153510373315.

Provoost, Rudy. 2009. "Philips Lighting." Royal Philips ElectronicsLighting Analysts' Day, Boston, September 24th, 2009.

Rao, P. M., Vijaya Vemuri, and Peter Galvin. 2004. "The Changing Technological Profile of the Leading ICT Firms: Evidence from US Patent Data, 1981-2000." Industry and Innovation 11 (4):353372. doi: $10.1080 / 1366271042000289351$.

Rosenkopf, Lori, and Paul Almeida. 2003. "Overcoming Local Search Through Alliances and Mobility." Management Science 49 (6):751-766.

Rosenkopf, Lori, and Atul Nerkar. 2001. "Beyond local search: boundary-spanning, exploration, and impact in the optical disk industry." Strategic Management Journal 22 (4):287-306. doi: 10.1002/smj.160.

Sanderson, S. W., K. L. Simons, J. L. Walls, and Y. Lai. 2008. "Lighting." In Innovation in Global Industries: US Firms Competing in a New World (Collected Studies), edited by J. T. Macher and D. C. Mowery. Washington, D.C.: The National Academic Press.

Sanderson, Susan Walsh, and Kenneth L. Simons. 2014. "Light emitting diodes and the lighting revolution: The emergence of a solid-state lighting industry." Research Policy 43 (10):17301746. doi: http://dx.doi.org/10.1016/j.respol.2014.07.011.

Sándor, N, and J Schanda. 2006. "Visual colour rendering based on colour difference evaluations." Lighting Research and Technology 38 (3):225-239. doi: 10.1191/1365782806/rt168oa.

Sathaye, Jayant, and Scott Murtishaw. 2004. Market failures, consumer preferences, and transaction costs in energy efficiency purchase decisions. Berkeley, CA: Lawrence Berkeley National Laboratory. 
Scholand, M.J. , and H.E. Dillon. 2012. Life-Cycle Assessment of Energy and Environmental Impacts of LED Lighting Products. Part 2: LED Manufacturing and Performance. Washington DC: U.S. Department of Energy, Office of Energy Efficiency and Renewable Energy.

Schreyögg, G., J. Sydow, and P. Holtmann. 2011. "How history matters in organisations: The case of path dependence." Management and Organizational History 6 (1):81-100.

Smet, KAG, WR Ryckaert, MR Pointer, G Deconinck, and P Hanselaer. 2012. "Optimization of colour quality of LED lighting with reference to memory colours." Lighting Research and Technology 44 (1):7-15. doi: 10.1177/1477153511432250.

Stettler, James, Alasdair Leslie, and Andy Bell. 2010. The future of lighting: who will win? London: New Street Research LLP.

Stuart, Toby E., and Joel M. Podolny. 1996. "Local search and the evolution of technological capabilities." Strategic Management Journal 17 (S1):21-38. doi: 10.1002/smj.4250171004.

Sydow, J., A. Windeler, C. Schubert, and G. Möllering. 2012. "Organizing R\&D Consortia for Path Creation and Extension: The Case of Semiconductor Manufacturing Technologies." Organization Studies 33 (7):907-936.

Sydow, Jörg, Georg Schreyögg, and Jochen Koch. 2009. "Organizational path dependence: opening the black box." Academy of Management Review 34 (4):689-709.

Szabó, F., P. Bodrogi, and J. Schanda. 2009. "A colour harmony rendering index based on predictions of colour harmony impression." Lighting Research and Technology 41 (2):165-182. doi: $10.1177 / 1477153509103067$.

Teece, David J. 1986. "Profiting from technological innovation: Implications for integration, collaboration, licensing and public policy." Research Policy 15:285-305.

Tushman, Michael, and Philip Anderson. 1986. "Technological Discontinuities and Organizational Environments." Administrative Science Quarterly 31:439-465.

Weiss, Martin, H. Martin Junginger, and Martin K. Patel. 2008. Learning energy efficiency experience curves for household appliances and space heating, cooling, and lighting technologies. Utrecht: Utrecht University.

Weiss, Martin, Martin Junginger, Martin K. Patel, and Kornelis Blok. 2010. "A review of experience curve analyses for energy demand technologies." Technological Forecasting and Social Change 77 (3):411-428. doi: http://dx.doi.org/10.1016/j.techfore.2009.10.009.

Veitch, Jennifer A, and Shelley L McColl. 1995. "Modulation of fluorescent light: Flicker rate and light source effects on visual performance and visual comfort." Lighting Research and Technology 27 (4):243-256. doi: 10.1177/14771535950270040301.

Vergne, J. P., and R. Durand. 2010. "The missing link between the theory and empirics of path dependence: Conceptual clarification, testability issue, and methodological implications." Journal of Management Studies 47 (4):736-759.

Wilkins, A.J., and C. Clark. 1990. "Modulation of light from fluorescent lamps." Lighting Research and Technology 22 (2):103-109. doi: 10.1177/096032719002200205.

Willoughby, A.H. 1974. "New lamps: their suitability for interior lighting." Lighting Research and Technology 6 (1):1-8. doi: 10.1177/096032717400600101.

VITO. 2009. Final report. Lot 19: Domestic lighting. Study for European Commission DGTREN unit D3. 2009/ETE/R/069. Mol: Flemish Institute for Technological Research NV (VITO). 


\section{Appendix: Input for analysis from different sources (in alphabetical order)}

\begin{tabular}{|c|c|}
\hline Source name & Input for analysis \\
\hline ALG (2012) & $\begin{array}{l}\text { CFL copied incandescent bulbs: process and } \\
\text { examples. }\end{array}$ \\
\hline Alvi et al. (2011) & $\begin{array}{l}\text { Solving technical issues of LED lamps related to } \\
\text { colour rendering. }\end{array}$ \\
\hline \multirow[t]{2}{*}{ Ashe et al. (2012) } & Push for more energy efficient lighting. \\
\hline & $\begin{array}{l}\text { Public awareness campaigns in support of energy } \\
\text { efficient technologies. }\end{array}$ \\
\hline Babcock (2009) & $\begin{array}{l}\text { Incandescent bulbs as an evaluation standard and } \\
\text { barriers for other technologies associated with that }\end{array}$ \\
\hline $\begin{array}{l}\text { Berman et al. } \\
\text { (1997) }\end{array}$ & $\begin{array}{l}\text { Solving technical issues of fluorescent lighting } \\
\text { related to flickering and modulation. }\end{array}$ \\
\hline $\begin{array}{l}\text { Bruxdrett et al. } \\
\text { (1973) }\end{array}$ & $\begin{array}{l}\text { Solving technical issues of fluorescent lighting } \\
\text { related to flickering and modulation. }\end{array}$ \\
\hline $\begin{array}{l}\text { Burgin and } \\
\text { Edwards (1970) }\end{array}$ & $\begin{array}{l}\text { Halogen lamps positioned as substitutes for } \\
\text { incandescent bulbs. }\end{array}$ \\
\hline $\begin{array}{l}\text { Gould and Cheng } \\
\text { (2011) }\end{array}$ & Cost dynamics of LEDs. \\
\hline
\end{tabular}

Lighting as a large scale industry: large investments in production facilities.

Hedekvist (2011)

Heidemann et al. (1993)

IEA (2006)

\section{Problems of LED fitting into existing fixtures.}

\author{
CFL copied incandescent bulbs: process and \\ examples.
}

Greater availability of incandescent bulbs in the stores compared to other technologies contributing to the popularity of incandescent bulbs.

Incandescent bulbs perceived as an evaluation standard in the eyes of consumers and barriers to other technologies caused by that.

CFL copied incandescent bulbs: process and examples.

Durability of fixtures and implications for lamp replacement patterns.

Problems of CFLs fitting into existing fixtures: examples and perceptions by consumers.

Reducing size of CFL to fit into fixtures: process and examples.
How data was used; what understanding was gained/improved

How the mechanism of adaptation of technologies to mimic incandescent bulbs was developed in the case of CFL.

What kind of learning effects could be driven by the technological characteristics of LED lamps.

What was driving the mechanism of sustained strive to improve energy efficiency of lighting technologies.

What was driving the mechanisms of consumer loyalty to incandescent bulbs and adaptation of technologies to mimic incandescent bulbs.

What kind of learning effects could be driven by the technological characteristics of fluorescent lamps.

What kind of learning effects could be driven by the technological characteristics of fluorescent lamps.

How the mechanism of sustained strive to improve energy efficiency of lighting technologies was developed.

How the mechanism of economies of scale was developed in the case of LED.

How the mechanism of sunk costs was developed.

What was driving the mechanism of adaptation of technologies to fit into existing fixtures in the case of CFL.

How the mechanism of adaptation of technologies to mimic incandescent bulbs was developed in the case of CFL.

How the mechanism of availability in stores of incandescent bulbs was developed.

What was driving the mechanisms of consumer loyalty to incandescent bulbs and adaptation of technologies to mimic incandescent bulbs.

How the mechanism of adaptation of technologies to mimic incandescent bulbs was developed in the case of CFL.

How the mechanisms of durability of lighting fixtures and of adaptation of technologies to fit existing fixtures were developed.

What was driving the mechanism of adaptation of technologies to fit into existing fixtures in the case of CFL.

How the mechanism of adaptation of technologies to fit into existing fixtures were 
Perception of lamps costs by consumers.

Iwafune (2000)

LEDs Magazine (2005)

LRC (2003)

Martinot and Borg (1998)

Menanteau and Lefebvre (2000)

OECD/IEA (2010) CFL Harmonization Initiative being crucial for solving customer acceptance problems.

Specific technology and market problems of CFL lamps.

Pousset et al. (2010)

Provoost (2009)

Sanderson and Simons (2014)

Sándor and Schanda (2006)

Sathaye and Murtishaw (2004)

Smet et al. (2012)

Solving technical issues of LED lamps related to colour rendering.

Stettler et al. (2010) Sales patterns of leading manufacturers. technological advances and market development for LED.

Solving technical issues of LED lamps related to colour rendering.

Reducing size of CFL to fit into fixtures. developed in the case of CFL.

How the mechanism of loyalty to incandescent bulbs was developed.

How the mechanisms of adaptation of technologies to mimic incandescent bulbs and to fit into existing fixtures were developed in the case of CFL.

How the mechanism of adaptation of technologies to mimic incandescent bulbs was reproduced in the case of LED.

How the mechanism of adaptation of technologies to mimic incandescent bulbs was developed in the case of CFL.

What was driving the mechanism of adaptation of technologies to fit into existing fixtures in the case of CFL.

What was driving the mechanisms of consumer loyalty to incandescent bulbs and adaptation of technologies to mimic incandescent bulbs.

What was driving the mechanism adaptation of technologies to mimic incandescent bulbs in the case of CFL.

What was driving the mechanism of adaptation of technologies to fit into existing fixtures in the case of CFL.

How the mechanism of building-up loyalty to CFL after demand-side management programs was developed.

What was driving the mechanism of following harmonized testing and performance specifications for CFL lamps.

What could potentially be driving a negative feedback mechanism in the case of CFL.

What kind of learning effects mechanisms could be driven by the technological characteristics of LED lamps.

What was driving the mechanism of sunk costs.

What was driving the mechanism of see-saw effects during LED advancement across a number of market niches.

What kind of learning effects mechanisms could be driven by the technological characteristics of LED lamps.

How the mechanism of adaptation of technologies to fit into existing fixtures was developed in the case of CFL.

What kind of learning effects mechanisms could be driven by the technological characteristics of LED lamps.

How the mechanism related to durability of lighting fixtures was developed. 
Manufacturers' costs of restructuring production facilities: example of Philips Lighting.

Szabó et al. (2009) Solving technical issues of LED lamps related to colour rendering.

Veitch and McColl Solving technical issues of fluorescent lighting (1995)

VITO (2009)

Weiss et al. (2008) Reducing size of CFL to fit into fixtures.

Weiss et al. (2010) CFL cost dynamics.

Wilkins and Clark (1990)

Willoughby (1974) Theoretical efficiency limits of white light in relation to future lighting technologies.
What was driving the mechanism of sunk costs.

What kind of learning effects mechanisms could be driven by the technological characteristics of LED lamps.

What kind of learning effects mechanisms could be driven by the technological characteristics of fluorescent lamps.

How the mechanism of adaptation of technologies to fit into existing fixtures was developed in the case of CFL.

How the mechanism of adaptation of technologies to fit into existing fixtures was developed in the case of CFL.

How the mechanism of economies of scale was developed in the case of CFL.

What kind of learning effects mechanisms could be driven by the technological characteristics of fluorescent lamps.

What was driving the mechanism of sustained strive to improve energy efficiency of lighting technologies. 